\title{
A MULTICRITERIA MODEL FOR SELECTING OF IT ACTIVITIES TO OUTSOURCE
}

\author{
Don Petkov* \\ Department of Business Administration \\ Eastern Connecticut State University \\ Willimantic, CT, USA \\ E-mail: petkovd@easternct.edu \\ Olga Petkova \\ School of Business \\ Central Connecticut State University \\ New Britain, CT, USA \\ E-mail: petkovao@ccsu.edu
}

\begin{abstract}
In this paper we are concerned with the decisions in IT outsourcing. Lacity and Willcocks provide after extensive empirical work three separate two dimensional decision models involving contributions of the IT activity to the business positioning, to the business operations; in-house scale and management practices; degree of IT integration and technology maturity. We propose a multicriteria model for the selection of IT activities to be outsourced that integrates the findings of Lacity and Willcocks and the concepts of AHP for better holistic decisions in IT outsourcing.
\end{abstract}

Keywords: Decision to outsource, AHP, Information Technology outsourcing.

\section{Introduction}

The importance of the decisions associated with implementing Information Technology (IT) outsourcing has been stressed in the literature (see Schniederjans (2007)). It is related to the contradicting evidence through various practitioner outlets like Gartner reports and others in favor and against outsourcing presented in Lacity and Rottman (2008). The discussion of the quality of IT outsourcing decisions in Palvia (2002) and Kakabadze and Kakabadze (2002) points to the need for its improvement. The need for multidimensional assessment of outsourcing decisions was first pointed in general terms by Ventakraman (1997).

Huizingh and Vrolijk (1996) pointed the potential for using a multicriteria decision making (MCDM) approach, the Analytic Hierarchy Process (AHP) (see Saaty,2008a) in IT outsourcing management as one of the Information Systems applications of AHP. Among some of the early applications of AHP to IT outsourcing could be listed Petkov and Petkova (1999), who propose a model for the selection of an outsourcing vendor; Udo (2000) and Yang and Hwang (2000) present models for IT outsourcing

* Corresponding author

ACKNOWLEDGMENT: The authors are grateful to Professor Thomas Saaty and Rozann Saaty for creating the global inspirational atmosphere for applying AHP for better decision making. 
decisions whose criteria are a synthesis of previous research in the IS outsourcing literature in the 1990s but whose structure is determined largely by the decision makers involved in the problem situation; Petkov and Petkova (2003), who use AHP as a vehicle to understand better the differences in the values of the clients and the outsourcing providers in a large IT project and others.

IT outsourcing decisions can be grouped into three categories: issues to whether to outsource the IT operations, including selection of activities to outsource; selection of outsourcing providers and decision related to aspects of the management of the relationship between the clients and the outsourcing providers. In this paper we are concerned only with the decision on whether to outsource an IT operation and choosing activities to outsource and do not consider the remaining types of outsourcing decisions.

The goal of this paper is to provide a better model for decision making in IT outsourcing and to point to the need to integrate MCDM applications to outsourcing with the conventional research in outsourcing management. The contribution of this work is that it provides an Analytic Hierarchy Process model for selection of activities to outsource whose structure is based on the best practices of managing IT outsourcing. It is flexible and can be applied in any organization by its managers. The paper proceeds with a brief overview of Analytic Hierarchy Process applications to decisions on whether to outsource and what activities to outsource, followed by a summary of the significant recent IS research publications on similar problems. Then an AHP model for deciding what activities to outsource is proposed on the basis of the best results in traditional IS research followed by concluding considerations.

\section{Recent AHP applications to decisions related to activities to outsource}

Pandey and Vasal (2004) propose two AHP models: one for making a choice of activities to outsource and another to choose the appropriate outsourcing methodology. For the first one they provide without any particular justification three criteria: criticality, stability and simplicity associated with the activities under consideration. These are verified subsequently through interviews with twenty IT managers. We may note however that there is no particular link between their work and past traditional research on IS outsourcing.

Hwang (2005) presents a web based decision support system using fuzzy AHP to assist in the make or buy decision. It proposes a web-based two-step approach: the first step uses AHP and the second step applies fuzzy set ranking methodologies to integrate the special decision problems involved. In spite of the fact that the author quotes the classical literature on the make or buy decision as a source for consideration during the brainstorming session of application of the proposed model. The AHP model however does not include any elements from the past research on the make or buy decision.

Wang and Yang (2007) have considered six criteria: economics, resources, strategy, risk, management and quality in their proposed use of a combination of AHP and PROMETHEE. Their literature review covers relevant traditional research in outsourcing and the derived criteria are based on it. However the criteria in their approach are determined at the end by a group of managers as is shown in Wang and Yang (2008) and hence it is hard to judge to what degree the knowledge of the managers involved reflects the state of the art on the decision whether to outsource or not.

Udo, Kirs and Bagchi (2008) provide an AHP model for evaluating what activities to outsource. They quote a practitioner source for justifying the criteria included in their model: the strategic importance of the IS function in question, economic considerations, project attributes, vendor issues, and industry or environment issues. While these criteria make sense in general they are based on a single source that is 
not reflecting fully the vast amount of IS research associated with IT outsourcing. It may be concluded that the quoted past research on applying MCDM to the IT outsourcing decision is based mostly on intuitive selection of criteria that are either not justified sufficiently or are based on earlier publications on IT outsourcing

\section{A brief review of traditional IT research on the outsourcing decision}

The following brief revue shows that mainstream IT outsourcing research has avoided the application of multicriteria approaches. Thus Benamati and Rajkumar (2003) present an empirical study applying the technology acceptance model to outsourcing decisions by considering the external environment, prior outsourcing relationships and perceived risks in outsourcing. While the technology acceptance model is a very important strand of IS research, it seems that it is insufficient for capturing the richness of factors affecting decisions to outsource.

Navarrete and Pick (2002) investigate selective IT outsourcing in the banking industry of Mexico. Their empirical analysis derives organizational, project and provider variables grouped in a descriptive framework of making IT outsourcing decisions including a total of 22 factors. While their findings are providing insights in the ways how outsourcing decisions are made in general they seem to be of little value for a manager due to the enormous number of factors involved and the lack of a framework for their application.

Two of the most influential researchers in IT outsourcing, Lacity and Willcocks (2001) provide as a result of extensive empirical work through interviews conducted over many years three separate two dimensional models as 2 by 2 matrices. It is hard to understand however how these models can be applied in practice only one at a time as the authors imply. Their study was the major factor motivating our research and this paper and the next section of the paper present further analysis of Lacity and Willcocks (2001) and our MCDM extensions of their ideas.

Palvia (2002) quotes a statement of a market research company that $70 \%$ of IT managers lack the experience to manage an outsourcing project in a way that maximizes shareholder value. This underlines the need for improvements both in outsourcing theory and in practice. One possible reason for the poor state of affairs in IS outsourcing management is that "many authors focus their interests only on some phases of the overall process of outsourcing " (Franceschini and Galetto, 2003:247).

Past publications on IS outsourcing management can be placed in two groups. The first one is bigger and is based on ongoing empirical and case study research generating broader outsourcing management guidelines to particular aspects of an outsourcing project. Lacity and Rottman (2008) among others have produced guidelines for offshoring work based on interviews with representatives from 25 client organizations, 33 supplier organizations and 10 offshore advisor firms. They focus mainly on the client organization in outsourcing and investigate seven roles of the client organization chief information officer (CIO): establish expected IT and business benefits, select the right approach to outsourcing, enamor suppliers by being an attractive client, communicate the outsourcing strategy to all stakeholders, provide enough resources to implement the sourcing strategy, build social capital with key supplier executives, seek independent assessment of sourcing strategy initiatives. While the roles are important for improved outsourcing decisions there is little guidance on how these decisions can be made in practice. In another book, Schniederjans (2007) investigates in-sourcing, outsourcing, the role of core competencies of a firm, the impact of good project management and the use of performance metrics and the balanced score cards for improvement of outsourcing management. 
The second group of IS outsourcing publications is smaller and refers to a few attempts to capture the whole IS outsourcing management process. This situation however is changing in more recent years when more and more papers and books attempt to address wider issues in IT outsourcing. Decision making is a crucial activity in management practice. A structured general model for the management of outsourcing processes is presented by Franceschini and Galetto (2003). They provide an integrated framework for making IT outsourcing decisions that combines benchmarking, multicriteria decision aid methods, cost analysis and other process planning methodologies. Their methodology is somewhat linear in nature but as a whole seems more realistic than traditional empirical IS research. A broader integrated framework for management of information technology outsourcing is presented by Fjemerstad and Saitta (2005). Yet another general decision framework to guide managerial decision making on IS outsourcing is presented in King (2008). While the latter is useful in focusing managerial attention to the relevant issues at every step of the whole process it does not provide any further guidelines on how decisions are made and that is another motivation for applying MCDM models in outsourcing.

The existing literature on outsourcing leads to a conclusion about the need for decision making associated with outsourcing that takes into account the conditions of the client, the outsourcing providers and any other relevant stakeholders. Outsourcing solutions that are appropriate in one instance may be counterproductive in others. This underlines the need to provide models that assist in decision making for a particular situation. The existing literature does not provide a particular procedure for making outsourcing decisions apart from general recommendations based on empirical research about the role of single factors. It can be noted that decisions like a selection of what components of the IT operation to be contracted, choice of a vendor, prioritization of the risks associated with outsourcing etc. are complex. They involve many criteria and different variables. The following section provides an AHP model for the selection of activities to outsource based on the work by Lacity and Willcocks(2001).

\section{An AHP model for selection of IT activities to outsource}

Lacity and Willcocks (2001) present probably the deepest investigation of offshoring practices based on 1500 interviews. In their chapter dedicated to the outsourcing decision, which is based on their earlier work Lacity et al. (1996), they provide three separate two dimensional models involving:

-contribution of the IT activity to the business positioning and contribution to the business operations;

-in-house scale and management practices with respect to the best industry practices;

-degree of IT integration and technology maturity.

While the depth of their findings is not questionable, we may conclude that their suggested three models can be replaced by a more practical integrated approach that is applicable to the conditions of a specific organization and combines the various quantitative and qualitative factors affecting a decision to outsource. Hence, we propose an AHP model that allows measurement of the impact of those factors in the conditions of a particular organization, supporting individual or group decision making on the problem. Our model is an improvement over the work by Lacity and Willcocks (2001) as it allows the use of AHP to prioritize the criteria and the potential activities for outsourcing utilizing the benefits provided by AHP listed below (see Saaty,1994).

- Allows the incorporation of multiple criteria.

- Provides a method for measuring quantitative and qualitative variables.

- Provides for transparency.

- Allows audit trail of the decisions. 
Candidate MCDA approaches to implement the model that we suggest here are the Simple Multi Attribute Rating Technique (SMART), Utility Theory and the Analytic Hierarchy Process (Saaty, 2004). We have chosen AHP as it is the most widely used MCDM approach (Yu and Chen, 2005) and also for the advantages of the pairwise comparison method that it utilizes as discussed in Saaty (2008a; 2008b). Various recent applications of AHP are listed in Saaty (2008b), while numerous earlier cases are presented in Saaty (1994).

Following the factors affecting selective outsourcing as defined by Lacity et al. (1996), an AHP model for the selection of the IT activities or services within the organization that are potential candidates for outsourcing is proposed here. It is a refinement of the ideas of Lacity and Willcocks (2001) and Lacity et al. (1996). The first two criteria in the hierarchy are associated by Lacity and Willcocks (2001) with the selection of the activities to outsource. The third and fourth criteria are abstractly linked to economic considerations of the outsourcing decision while the fifth and the sixth are linked to the selection of an appropriate contract (Lacity et al., 1996).

The fragmented consideration of the above six criteria in the three $2 \times 2$ models in Lacity and Willcocks (2001) seems unnatural. It is complicating the decision making process and implies that managers work separately with each $2 \times 2$ model. One cannot easily evaluate the impact of all six criteria if they are considered in groups of two as Lacity et al. (1996) seem to suggest. Hence the need to integrate all the criteria above in one model as suggested below.

\section{FIRST TWO LEVELS OF A HIERARCHY FOR THE SELECTION OF AN ACTIVITY TO BE OUTSOURCED}

\author{
Main goal \\ Best \\ candidate \\ for \\ outsourcing
}

\author{
Criteria \\ Contribution of IT activity to business operations \\ Contribution of IT activity to business positioning \\ Importance of best managerial practices for the activity \\ Possibility for achieving economies of scale \\ Degree of technological maturity of the activity \\ Degree of integration with other business activities
}

Other elements in the analytic hierarchy for outsourcing activity selection at the next levels are:

- Third level - intensities for measuring the criteria.

- Fourth level - possible alternatives, the activities considered for outsourcing.

We may note that up to third level the decision makers use pairwise AHP comparisons using the 1-9 scale (Saaty, 1994, Saaty, 2008a), while at the last level is used absolute comparison mode (see Saaty, 1994). Further details on the foundations of AHP may be found in Saaty(1994) and Saaty (2008b).

The proposed approach is a better decision model for outsourcing decisions as it provides a decomposition of the complex problem of selecting activities to outsource into many smaller tasks associated with pairwise comparisons of factors in the hierarchy, it provides for control of subjectivity and potential inconsistencies in the judgments (Saaty, 2008a) and ensures greater acceptance and legitimacy of the decisions.

The first two criteria in our model and in Lacity and Willcocks (2001) are very similar to the two criteria 
considered in King (2008) in his framework for outsourcing decisions: core competences of the organization and critical success factors. Since Lacity and Willcocks (2001) include not just two but six criteria, we believe that building our AHP model along their work provides for a better multifaceted decision model than one using the ideas of King (2008).

The steps to apply the model in a particular organization are based on ideas in Saaty (1994) and include:

- Stakeholder identification and ensuring their relevant representation

- Problem identification within the group of stakeholders.

- Initial analysis of options.

- Criteria and factor definition for the model based on the work of Lacity and Willcocks(2001).

- Pairwise comparisons of the criteria by the relevant managers or an IT steering committee that reflect the management priorities.

- Gathering of data on the factors and the activities to outsource and placing them in tables structured according to the chosen criteria and factors

- Conducting a series of meetings with groups of stakeholders to capture their values in the form of judgments regarding the pair-wise comparisons between the factors involved.

- Use AHP software for calculation of the local priorities of factors in the hierarchy and synthesis of the global priorities of each factor and alternative.

A similar model was applied in practice to the selection of what IT activities to outsource within a Central Applications Office for all universities in the province of Kwa Zulu Natal, South Africa. Numeric details on the case are not presented for space reasons and they are not essential for the main ideas of the paper. A summary of our experiences in applying the model is provided below:

- The use of the multi-criteria approach introduced a disciplined way of thinking for the large stakeholder group.

- The transparency of the process enhanced the legitimacy of the conclusions.

\section{Conclusions and future research}

The MCDM approach provides a richer multidimensional perspective for understanding outsourcing decisions. Possible future work includes the need to assess how interdependent are the factors involved in the model and if relevant, the possible application of the Analytic Network Process (see Saaty, 2008a) for its evaluation.

Saaty (2008a) indicates the need in future work in AHP to "integrate and catalogue of the structure of a variety of carefully studied decisions to create a dictionary to serve as a source of reference for others to consult, so they can benefit from the knowledge that went into making these decisions". However our literature review on MCDM applications to outsourcing decisions raise an issue about the quality of the models to be considered for such a catalogue. We found that past research on applying MCDM to the IT outsourcing decision is based mostly on an intuitive selection of criteria that is not always justified sufficiently or not grounded well in traditional IS research on IT outsourcing. The challenge is to integrate best practices and the body of knowledge in traditional decision making associated with a particular problem area with the expressive power of AHP modeling. This idea emerged intuitively from our analysis. It is somewhat similar to the ideas of $\mathrm{Yu}$ and Chen (2005) who suggested empowerment of AHP for a given problem by expanding its competence set with skills, ideas, knowledge and information for solving a problem successfully (note that a competence set for a problem is a Habitual Domain projecting to a particular problem according to Yu and Chen (2005:9)). Hence further success in AHP modeling will depend on how successfully such models capture the habitual domain for a particular problem. 
To improve decision making in outsourcing a practical approach is needed that integrates the findings from extensive empirical research in IT outsourcing management with MCDM ideas. Such an approach needs to reflect the knowledge base associated with outsourcing management (see further discussion of its content in King (2008)) and has to be applicable to the conditions of a specific organization, combining the various quantitative and qualitative factors affecting a decision to outsource. This paper proposes a holistic multicriteria model for the selection of IT activities to be outsourced which integrates the models for outsourcing decisions by Lacity and Willcocks (2001), representing the deepest insights in traditional IT management research, with the power of AHP modeling (see Saaty (2008a; 2008b)). The results from this research aim to contribute to improvement of decision making in IT outsourcing.

\section{REFERENCES}

Benamati, J. and Rajkumar T. (2003), An Empirical Study of the Applicability of the Technology Acceptance Model to Application Development Outsourcing Decisions, AMCIS 2003 Proceedings paper 203.

Fjermestad, J. and Saitta, J. (2005). A Strategic Management Framework for IT Outsourcing: A review of the Literature and the Development of a Success Factors Model, Journal of Information Technology Cases and Applications Research, 7,3 (2005).

Franceschini, F., Galetto, M., Pignatelli, M. and Varetto, M. (2003). Outsourcing: guidelines for a structured approach, Benchmarking: an International Journal, vol 10, No 3, 246-260.

Huizingh, E.K.R.E. and Vrolijk, H.C.J. (1996). Decision Support for Information Systems Management: Applying Analytic Hierarchy Process, Proceedings ISAHP, Vancouver.

Hwang, H.S., (2005), Web -Based Multiattribute Analysis Model for Make or Buy Decision, Proceedings ISAHP 2005, Honolulu.

Kakabadze, N. and Kakabadze, A. (2002). Software as a Service via Application Service Providers (ASPs)Model of Sourcing: An Exploratory Study, Journal of Information Technology Cases and Applications, Vol 4, No.2, 26-44.

Lacity, M.C. and Rottman, J. (2008), Offshore Outsourcing of IT Work: Client and Supplier Perspectives, Pallgrave-Macmillan.

Lacity, M.C. and Willcocks, L.P. (2001). Global Information technology Outsourcing: In Search of Business Advantage, Wiley.

Lacity M. C., Willcocks L P and Feeny D F. (1996). The value of Selective IT Outsourcing, Sloan Management Review, Spring, 13-25

Navarrete, C. J. and Pick, J. (2002), Initial Selective Information Technology Outsourcing: An Exploratory Study of Cases Of Large Organizations In Mexico. Journal of IT Cases and Applications, Vol 4, No 1.

Palvia, S.C.J. (2002). Is e-Commerce Driving Outsourcing to Its Limits?, Journal of Information Technology Cases and Applications, Vol. 4, No.1, 1-5. 
Pandey, V. and Bansal, V. (2004). A Decision-Making Framework for IT Outsourcing using the Analytic Hierarchy Process, Proc. International Conference on Systemics, Cybernetics and Informatics, NISIET, Government of India, 1-VII

Petkov, D. and Petkova O., (1999). Making Decisions in Information Technology Outsourcing, Fifth International Conference of the Decision Sciences Institute, Athens, Greece, July 1999

Petkova O and Petkov D, (2003). Factors Affecting Software Development Productivity in an Outsourced IT Project, Journal of Information Technologies Cases and Applications, Vol5, No1, 5-22.

Saaty T. L. (1994). Fundamentals of Multiple Criteria Decision Making with the Analytic Hierarchy Process, RSW Publications, Pittsburgh, 1994.

Saaty, T.L. (2008a). Decision Making with the Analytic Hierarchy Process, International Journal of Services Sciences, vol 1 (1), 83-98.

Saaty, T.L. (2008b). Relative Measurement and Its Generalization in Decision Making Why Pairwise Comparisons are Central in Mathematics for the Measurement of Intangible Factors The Analytic Hierarchy/Network Process, RACSAM Rev. R. Acad. Cien. Serie A. Mat., VOL. 102 (2), 2008, 251-318.

Schniederjans , D.G. (2007). Outsourcing management information systems, IGI Global, Hershey.

Udo, G.G. (2000). Using analytic hierarchy process to analyze the information technology outsourcing decision. Industrial Management \& Data Systems,100(9), 421-429.

Udo, G., Kirs, P, Bagchi, K., (2008). Comparing Outsourcing Options for Software Development Projects Using the Analytic Hierarchy Process, Proceedings 2008 Decision Sciences Institute Conference.

Venkatraman N. (1997). Beyond Outsourcing: Managing IT Resources as a Value Centre, Sloan Management Review, Spring, 51-64.

Wang, Jian-Jun and Yang, De-Li, (2007). Using a hybrid multi-criteria decision aid method for information systems outsourcing. Computers and Operations Research, vol. 34, No. 12, 3691-3700.

Wang, Jian-Jun, Lin, Z-L. and Huang, H. (2008), A Decision Model for Information Systems Outsourcing: Using a Multicriteria Method, Journal of Service Sciences \& Management. 2008, 1: 1-9

Yang, C. and Huang, J-B. (2000). A Decision Model for IS Outsourcing, International Journal of Information Management, Vol. 20, Iss.3, 225-239.

Yu, P.L. and Chen, Y.C. (2005). Empowering Analytic Hierarchy Process by Habitual Domain Concepts, Proceedings of the $8^{\text {th }}$ ISAHP. 